\title{
Mulemba
}

Revista Angolana de Ciências Sociais

6 (11) | 2016

Políticas, direitos e práticas da sociedade e do Estado

\section{A necessidade de formação didáctico-pedagógica do professor universitário principiante}

The need for didactic-pedagogical training of the beginning university professor

\section{António Inácio Rocha Santana}

\section{(2) OpenEdition}

1 Journals

\section{Edição electrónica}

URL: http://journals.openedition.org/mulemba/1459

DOI: 10.4000/mulemba.1459

ISSN: 2520-0305

\section{Editora}

Edições Pedago

\section{Edição impressa}

Data de publição: 1 maio 2016

Paginação: 165-192

ISSN: 2182-6471

\section{Refêrencia eletrónica}

António Inácio Rocha Santana, «A necessidade de formação didáctico-pedagógica do professor universitário principiante», Mulemba [Online], 6 (11) | 2016, posto online no dia 01 outubro 2018, consultado o 26 janeiro 2021. URL: http://journals.openedition.org/mulemba/1459 ; DOI: https:// doi.org/10.4000/mulemba.1459 


\title{
A necessidade de formação didáctico-pedagógica do professor universitário principiante
}

\begin{abstract}
António Inácio Rocha Santana*
Resumo: Este texto visa abordar a questão relacionada com a formação do professor universitário principiante, tendo em conta que a tarefa da educação em Angola é promovida por desafios que estimulam os pedagogos a reflectir em um ensino superior rigoroso e objectivo capaz de proporcionar ao cidadão uma formação com qualidade. Mas, evidências empíricas do exercício docente apontam que, para que este desiderato se concretize, é preciso abandonar a perspectiva actual em que, por exemplo, professores principiantes começam a leccionar como docentes titulares de cadeiras sem o devido acompanhamento de um professor experiente, bem assim como, tornar obrigatório o certificado de agregação pedagógica.
\end{abstract}

Palavras-chave: Formação, didáctica, pedagogia, actividade, professor principiante.

\section{Introdução}

Durante muitos anos predominou no contexto do ensino superior uma forte convicção de que, para se tornar um bom professor neste nível do magistério, bastava ser um exímio comunicador e possuir conhecimentos aprofundados sobre a disciplina que pretendesse lecionar. A justificação desta asserção apoiava-se no facto de a maioria dos estudantes do ensino superior serem adultos, contrastando com a população discente do ensino geral, composto maioritariamente por crianças e adolescentes. Pensava-se que

Sociólogo. Director-Geral da Escola Superior Pedagógica do Kwanza Norte e docente do Departamento de Sociologia (Ds) da Faculdade de Ciências Sociais (FCS) da Universidade Agostinho Neto (UAN). 
aqueles estudantes não necessitariam tanto da ajuda de pedagogos. Os estudantes universitários, por já possuírem uma «personalidade formada» e saberem o que pretendem, acreditava-se (como alguns ainda hoje acreditam) que não exigiriam de seus professores mais do que competências para transmitir os conhecimentos e para sanar suas dúvidas.

Por esta razão, até recentemente, havia uma despreocupação completa e explícita das autoridades educacionais com a preparação didático-pedagógica de professores para a docência no ensino superior, havendo, porém, preocupação no tocante a preparação de pesquisadores, ficando subentendido que quanto melhor pesquisador fosse, mais competente professor seria (GIL 2011). Porém, a estrutura formativa dos programas de pós-graduação, que oferecem este tipo de formação aos candidatos a professor universitário, afasta os pósgraduandos de qualquer discussão concernente ao tema pedagógico.

O trabalho aqui apresentado discorre sobre a questão seguinte: por que é necessário a formação didático-pedagógica do professor universitário principiante?

A falta de formação didáctico-pedagógica do professor universitário principiante dificulta sua ação docente. O dia-a-dia nas salas de aulas tem demonstrado, a todos os intervenientes do processo educativo, que o professor, quer universitário quer de outro nível, carece, proporcionalmente, tanto de sólidos conhecimentos da disciplina que aspira lecionar quanto de competências pedagógicas bastantes para permitir o desenvolvimento eficaz do processo de ensino-aprendizagem.

As insuficiências na formação didáctico-pedagógica do professor universitário são desveladas em cada ano letivo nos depoimentos feitos pelos estudantes. Um dado adquirido nesses depoimentos é que «a maioria das críticas em relação aos professores refere-se à falta de didáctica». Por esta razão é que «muitos professores $e$ postulantes à docência em cursos universitários vêm realizando cursos de didáctica do ensino superior, que são oferecidos em nível de pós-graduação, com uma frequência cada vez maior, por instituições do ensino superior» (GIL 2011: 1-2). No contexto angolano, por exemplo, para aos candidatos à docência superior é obrigatório apresentar o certificado de agregação pedagógica, mas essa orientação normativa raramente é observada.

O texto a seguir está estruturado da seguinte forma: no primeiro momento, apresenta-se alguns conceitos sobre didáctica e, de seguida, 
uma síntese sobre o contexto institucional de iniciação do professor principiante; no segundo, procura-se situar a didáctica no contexto de formação do professor universitário; no terceiro, discute-se a necessidade de se desenvolver no professor principiante as competências docentes para ensinar; no quarto momento, procura-se situar o papel do professor universitário face às exigências da sociedade da informação; finalizando, traz-se uma síntese do que foi discutido bem como algumas perspectivas.

\section{Conceito de didáctica}

O termo didáctica é de origem helénica e provém da palavra didaktiké, que exprime em sua essência a ideia de ensinar tudo o que se deve saber, tal como concebido pelo seu difusor Jan Amos Comenius (1592-1670) na obra Didáctica magna ou Tratado da arte universal de ensinar tudo a todos, publicada em 1657. Na actualidade, existem distintas definições de didáctica, mas em todas elas encontramos um atributo comum: todas as definições consideramna como ciência, técnica ou arte de ensinar.

A definição reportada no Dicionário Integral de Língua Portuguesa refere-se à didáctica como «a ciência auxiliar da pedagogia que promove os métodos mais adequados para a aprendizagem». Para destrinçar conceitos, Gil (2011: 2) ressalta que «a pedagogia é conhecida como a arte e a ciência da educação, enquanto a didáctica é definida como a ciência e a arte do ensino».

Masetto (1997: 13) considera a didáctica como «o estudo do processo de ensino-aprendizagem em sala de aula e de seus resultados», porquanto emerge, como refere Libâneo (1994: 58), «quando os adultos começam a intervir na actividade de aprendizagem das crianças e jovens através da direcção deliberada e planejada do ensino, ao contrário das formas de intervenção mais ou menos espontâneas de antes». A definição literal de didáctica, na sua dupla raiz (docere: ensinar e discere: aprender), corresponde à evolução de dois vocábulos essenciais, dado que ao mesmo tempo as actividades de ensinar e aprender apelam à interação entre os agentes que as realizam. Desde uma visão activa-participativa da didáctica, o docente (de docere) é que ensina, mas ao mesmo tempo é o que mais aprende neste processo de melhoria contínua da tarefa de coaprender com os colegas e os estudantes. A segunda acepção tem 
a ver com a voz discere, que faz menção ao que aprende, capaz de aproveitar um ensino de qualidade para compreender a si mesmo e dar resposta aos desafios contínuos de um mundo em constante transformação.

\section{O professor principiante e o contexto institu- cional}

Hoje, é amplamente aceite que o sucesso do processo de ensinoaprendizagem depende em grande parte da qualidade dos professores que levam a cabo esse processo. E a qualidade, por sua vez, é uma função da formação que recebem; não só a formação inicial (a teórica e a prática), que é dada em sala de aula da universidade, mas a de todo o processo posterior de desenvolvimento profissional contínuo, crescimento profissional, a ser produzido ao longo de sua carreira docente. E aceita-se também que o período de iniciação à prática profissional não é só influente, mas decisório, e até determinante, essencialmente o primeiro ano de docência responsável. Medina e Salvador (2009) denominam este período como o de «indução», em que se dirige uma atenção especial para os professores principiantes, em primeiro lugar, para reter os melhores na docência universitária, e, em segundo lugar, por tratar-se de uma ponte entre a formação inicial e o desenvolvimento profissional, um tempo em que os professores têm de aprender a articular teoria e prática.

Apela-se à necessidade de, também, prestar uma esmerada atenção tanto aos processos de socialização quanto ao aprender a ensinar dos professores «novatos», porque é nos primeiros anos de exercício que estes professores aprendem a ser professores. Os professores noviços, por um lado, têm de conhecer o quadro de valores, atitudes, interesses, habilidades e conhecimentos (competências) que constitui o que se convencionou chamar «cultura profissional», embora não passivamente, mas interagindo com outros indivíduos e instituições para fazer valer, por sua vez, seus propósitos. Por outro lado, devem adquirir a perícia profissional necessária para gerir adequadamente aqueles domínios em que hão de desenvolver sua tarefa, essencialmente a classe e os grupos de estudantes por que passam, aprendendo a processar as informações, a modificar suas crenças anteriores com base nas necessidades que a prática coloca, a 
criar uma ponte suficientemente resistente entre a teoria aprendida nos cursos de formação inicial e a prática que têm para desenvolver.

Mas tudo isso, certamente, deve vir apoiado por acções dos gestores das Instituições de Ensino Superior (IEs), que têm essa responsabilidade, e, sobretudo, pelos professores. Eles deverão criar nas IEs um ambiente adequado para que estes processos se produzam, não sem obstáculos mas com a garantia da facilitação, o apoio e as ajudas que se afiguram como necessárias e apropriadas. É o próprio colectivo de professores e administrativos das IEs que tem a primeira responsabilidade em apoiar os seus docentes noviços, procurando meios e recursos, proporcionando os tempos imprescindíveis, em última análise, a criação de uma verdadeira cultura profissional que facilite a imersão do neófito na carreira docente.

\section{A necessidade de formação didáctica do profes- sor principiante}

Muitos estudantes confrontam-se hoje com situações desafiantes provocadas por variadas disfunções familiares, por uma cultura cada vez mais complexa e, à partida, mais ambígua, com relação aos aspectos éticos e morais, e por currículos escolares não sincronizados com o estilo de aprendizagem baseado na tecnologia mais avançada. E, sem dúvida, o professor necessita estar ligado a eles para que a sua tarefa recolha os resultados pretendidos por todos e, certamente, reclamados pela sociedade. E quanto mais complexa for a sociedade mais vigorosa será a demanda por um ensino de qualidade provedor dos meios intelectuais, morais e afectivos que permitam ao cidadão não somente se desenvolver no meio social em que há-de viver, mas também desfrutar de uma vida digna. Mas «isso supõe romper com certas ideologias institucionais que perduraram, ainda que parcialmente, durante muitos anos» (IMBERNÓN 2005: 96).

Nos últimos tempos, os políticos e os educadores têm feito grandes esforços para melhorar a educação, pelo que têm vindo a introduzir alterações que conduzam a um progresso contínuo tanto a respeito do que os alunos aprendem quanto na forma como são ensinados; os padrões de aprendizagem têm alcançado níveis cada vez mais elevados e as necessidades sociais e culturais exigem níveis mais elevados de preparação. E tudo isso leva a colocar o professor 
no centro das reformas dos sistemas de ensino e até mesmo das inovações promovidas pelas próprias instituições de ensino. $\mathrm{O}$ desenvolvimento profissional dos professores tornou-se, assim, o eixo de todas as iniciativas.

Os principiantes têm expectativas e crenças pouco objectivas acerca do ensino, dos estudantes, da estrutura e organização das IES e das dificuldades com que inevitavelmente vão deparar na docência, expectativas e crenças condenadas a colidir com a dura realidade das salas de aulas. Também lhes é dada uma visão demasiado simples do ensino e, igualmente, é-lhes ocultado em grande parte o quadro que conforma a cultura interna das IEs, de modo que em nada é amortecido seu idealismo nem se melhora seu conhecimento sobre o trabalho real desenvolvido nestas instituições; poucos acabam sabendo acerca de toda esta série de forças organizativas, administrativas e interpessoais de que receberão uma forte influência em suas vidas como professores.

Além disso, os programas de formação têm sérias limitações, pois baseiam-se tradicionalmente num currículo de formação constituído em torno de uma certa formação teórica combinado com cursos de pós-graduação de curta duração e algumas experiências de campo, esquecendo tanto o trabalho diário como os contextos sociais e políticos das instituições de ensino. Tudo isto, unido à falta de apoio que os novatos encontram nas instituições, a falta de tempo para a reflexão, a escassa ajuda para sua socialização e a falta de mentores que os assessorem, torna difícil sua integração no mundo do ensino e a construção de seu conhecimento profissional.

A preparação de excelentes professores é, por tudo isso, uma tarefa inevitável em todos os âmbitos e níveis de ensino; obter professores altamente treinados e responsáveis é algo atraente de forma incremental. Apela-se cada vez com mais afinco à necessidade de os professores conhecerem a matéria que ensinam, que possuam a habilidade necessária para comunicar de uma maneira efectiva o conhecimento que é básico para o aluno, que sejam capazes de proporcionar os meios apropriados para desenvolver em seus estudantes um pensamento avançado e que disponham das competências que se exigem a fim de aperfeiçoarem habilidades para a resolução de problemas. Sabe-se que:

«O professor universitário tem estado empenhado em realizar uma docência encaminhado ao saber académico, necessário e cada 
vez mais copioso e globalizado, mas insuficiente para dar resposta aos novos desafios da sociedade do conhecimento, às necessidades do emprego e às mudanças exponenciais nos estilos e modos de desempenhar a vida laboral, absorvida pelo uso das TIC [tecnologias da informação e da comunicação], assim como a incidência das redes sociais e a transformação contínua da cultura, das organizações e dos múltiplos cenários sócio-laborais, com diferentes culturas e modos de resolver os problemas» (MEDINA et al. 2011: 123).

Contudo, estudos mostram que são as expectativas do professor as que contribuem em maior grau para a consecução da excelência (НАмzAн et al. 2008). Mas, além disso, exige-se um crescimento profissional contínuo, ao qual se deve prestar uma atenção especial, um crescimento que se há-de acrescentar na etapa de indução à prática. Um desenvolvimento profissional contínuo contra períodos típicos de formação de curta duração; um desenvolvimento profissional que implique uma aprendizagem ativa e integrada na vida diária da aula e da instituição de ensino; um desenvolvimento profissional, em última análise, fundamentado na participação colectiva em actividades de formação e facilitação da comunicação entre professores.

Não se pode ignorar que os professores inexperientes, que iniciam uma longa caminhada pela profissão, encontrarão múltiplas dificuldades que com certeza uma sala de aulas vai lhes proporcionar, havendo, por isso, necessidade de organizar previamente um programa de formação de desenvolvimento profissional. Em algumas instituições este programa é concebido a partir de modelos de pós-graduação de curta duração.

É necessário desenvolver nos neófitos uma cultura de contínuo crescimento, de aprendizagem ao longo de toda a vida, muito antes de darem início ao primeiro ano de exercício profissional. E tudo indica que a melhor forma de promover uma atitude positiva para a aprendizagem ao longo da carreira é através dos programas de indução, programas que estejam centrados não somente no treinamento, mas também na busca do bem-estar e apoio ao docente novel. Programas que proporcionam treinamento sistemático durante os primeiros dois ou três anos de exercício, com o apoio dos departamentos ou áreas de formação avançada e pós-graduação, através de cursos, seminários, e procedimentos de supervisão e acompanhamento durante o processo de ensino, assim como possibilidades de visita a outros professores e instituições de ensino. 
A supervisão - entendida como uma relação, como «uma viagem que descreve uma relação única entre um estagiário $e$ um professor [...]» (Awaya et al. 2003 apud MEdina e SAlvador 2009: 460) - ajuda os professores principiantes em seu desenvolvimento, aumenta a probabilidade de retenção na profissão do ensino e melhora a competência profissional dos assistidos. Desta maneira, é possível ajudar os novos professores a criarem seus modelos de ensino, a estabelecerem procedimentos efectivos de gestão de aula, a dominarem as rotinas e as práticas da instrução, a desenvolverem um sentimento de serem "aprendizes de toda a vida», a serem sensíveis aos problemas da comunidade, a compreenderem os problemas desta e para que sejam co-participes de uma verdadeira comunidade de aprendizes (DE VicENTE 2000a).

Os professores enfrentam, quando entram pela primeira vez no seu local de trabalho, novos desafios e responsabilidades, precisamente no momento em que têm de encontrar um lugar na cultura da instituição. Há, portanto, necessidade de dar tratamento adequado aos factores de socialização que influenciam seus sistemas de crenças e suas condutas, e uma resposta adequada aos seus interesses e problemas, para que se reduza, até uma escala baixíssima ou nula, a frustração, a ansiedade, o isolamento e o sentimento de dúvida constante na sua força de vontade. Porque estes docentes novatos sentem-se isolados, mas com um desejo intenso de serem aceites pelos estudantes, pelas direcções dos cursos, pela directoria da instituição e pelos seus colegas. Percebe-se, por exemplo, que os novos professores receiam solicitar ajuda, porquanto fazê-lo seria equivalente a admitir seu fracasso (MEDINA e SALVADOR 2009).

Mas, a que chamamos indução nos processos de formação dos professores?

Por indução à prática profissional, Medina e Salvador (2009: 450) entendem

«[...] um processo através do qual a instituição de ensino planifica sistematicamente para seus professores principiantes programas de desenvolvimento profissional que os ajudem a socializar-se no campo profissional, e os auxiliam para confrontar-se aos seus problemas quotidianos, reforçando sua autonomia pessoal e profissional, e facilitando seu aperfeiçoamento contínuo». 
Nesta definição podemos encontrar, em primeiro lugar, um aspecto de crucial importância: considera-se a instituição de ensino como um centro de treinamento, com todo significado que isto envolve para o desenvolvimento da reflexão partilhada, para a cooperação entre profissionais, para o apoio mútuo entre professores (muito mais favorável e benéfico para o principiante do que para o especialista). Em segundo lugar, na definição adoptada sublinha-se um especial reforço da autonomia pessoal dos docentes, quer dizer, entende-se o treinamento, não como um livro de receitas para uso do novo professor, mas algo que facilita a resolução autónoma dos problemas da sala. Em terceiro lugar, concebe-se o desenvolvimento profissional como um contínuo, de maneira que, à conclusão do processo de formação inicial, os professores não são um produto acabado, não são «professores para toda a vida», mas que ao longo da sua carreira profissional - a partir do momento da entrada na profissão de ensino até à jubilação - podem aprender muitas coisas de maneiras diferentes, mas essencialmente de outros profissionais.

Mas convém dizer que a cultura que predomina nas instituições de ensino é o individualismo fragmentado, utilizando uma terminologia de Hargreaves, que significa que os professores se encontram em situações geralmente de isolamento, sem comunicação efectiva e sistemática entre eles, sem tempo alocado para observarem e analisarem seu ensino. Isto, que é grave em qualquer professor e em qualquer nível de ensino, aumenta sua importância quando se refere a professores principiantes, que nunca orientaram uma aula com plena responsabilidade sobre o grupo de alunos, embora tenham tido períodos mais ou menos prolongados de práticas educativas durante sua formação inicial. E, neste tempo, o neófito encontra-se sozinho, a tal ponto que a literatura se refere a abandonos ou desistências da profissão por professores potencialmente efectivos.

Em Angola, a falta de apoio é total, de modo que é pressuposto no recém-chegado à docência do ensino superior uma perícia similar à que pode possuir um professor com vários anos de experiência no ensino. Todos os anos são admitidos para o quadro docente os estudantes com bom aproveitamento académico (embora nem sempre sejam os melhores, já que o critério de selecção é baseado na média final curricular), que, apesar de lhes ser atribuída a categoria de assistente estagiário e sem experiência, começam a leccionar como docentes titulares de cadeiras e sem o acompanhamento de um professor experiente. 
Espera-se que a socialização destes professores ocorra por simples contacto com os experientes, contactos sistemáticos tidos em situações não programadas. E também é esperado que desenvolvam o seu trabalho com a mesma eficiência que o experiente, pois presume-se que a preparação inicial proporcionada pela universidade é o suficiente para o iniciante aderir à prática com o domínio das habilidades, capacidades, e dos conhecimentos próprios do especialista.

Parece claro, no entanto, que, pelo menos, a preparação prática dos futuros professores revela deficiências, relacionadas, por exemplo, com a falta de envolvimento dos supervisores, tutores ou orientadores, devido à escassez de tempo (partilhado com palestras, com a supervisão de dissertações de mestrado, teses de doutoramento, com publicações, pesquisas e outras tarefas administrativas e de gestão). Por outro lado, a tarefa de controlo não é bem recompensada nem bem vista, porque os professores universitários acreditam que contribuem mais e melhor para a universidade a partir da pesquisa e do desenvolvimento da teoria.

Além disso, parece haver pouca coordenação entre os supervisores universitários e os professores cooperantes que auxiliam os alunos em escolas transmitindo alguns conhecimentos e experiências aos novos professores para que eles possam lidar com os problemas de comportamento e gestão (GAL 2006). Por outras palavras: está provado que há falta de comunicação entre os programas académicos que são ministrados na universidade e a prática que se desenvolve nas instituições de ensino geral. Neste sentido, Soares et al. (2008) apela a uma maior formação dos supervisores e um seguimento mais formal da transição de estudante a professor.

O que se tem observado é que a entrada do novato na sala de aula como gerente e responsável exclusivo de um grupo de estudantes ocorre abruptamente. Veenman (1984) cunhou o termo «choque de realidade», e Kelchtermans e Ballet (2002: 105) falam de «choque da práxis», que significa «a confrontação dos professores com as realidades e responsabilidades de ser um professor de classe que testa suas crenças e ideias sobre o ensino, desafia algumas delas e confirma outras». É um tempo em que os professores vivem um verdadeiro conflito entre as ideias proporcionadas a partir da experiência como alunos e dos conhecimentos adquiridos na universidade - ideias ingénuas sobre o processo de ensino-aprendizagem -, por um lado, e a experiência prática, por outro; um conflito - que pode desembocar em crises e até mesmo chegar ao abandono da 
profissão - entre o conhecimento prévio arrastado de sua formação inicial e a nova informação que vem jorrando de sua prática profissional; um conflito, no entanto, que alguns consideram a origem de alterações cognitivas provocadoras da construção do conhecimento didático. É o momento em que o professor necessita de formação para desenvolver competências para aprender a ser professor; é o tempo de indução para a prática profissional.

Também é frequente a atribuição de matérias diversificadas aos professores principiantes, em semestres seguidos, quando é mais provável que aprendam repetindo e afinando estratégias e explicações sobre os mesmos conteúdos, o que pode ajudar o fortalecimento fácil destes elementos nos seus esquemas cognitivos. Outras vezes, têm sido atribuídas aos principiantes - por necessidades organizativas - matérias para as quais não estão plenamente preparados, matérias para cujo ensino os principiantes não possuem o conhecimento didáctico necessário do conteúdo, pois carecem ainda da habilidade necessária para transformar essas matérias numa cadeia de actividades de aula promotoras de factores de aprendizagem. Muitas vezes, atribuem aos professores principiantes aquelas matérias e grupos de estudantes que apresentam mais dificuldades, porque é o «tempo de casa» o critério essencial estabelecido pelas instituições de ensino para que os professores façam as suas escolhas. Em todos os casos aqui apresentados, é indubitável que os professores principiantes possam encontrar o processo de aprender a ensinar muito dificultado, quando não obstaculizado.

Os professores que se confrontam com as demandas da aula não somente têm de estar imersos na matéria que ensinam, mas têm de possuir também as habilidades de comunicação apropriadas para passar com facilidade aos estudantes o conhecimento básico e para despertar primeiro e desenvolver depois neles um pensamento crítico e capacidade de resolução de problemas. As demandas sociais - como, por exemplo, o apelo da sociedade por um ensino de qualidade - geram continuamente novas expectativas em relação ao comportamento e à qualidade do corpo docente, ao mesmo tempo que exigem maiores níveis de aproveitamento académico dos estudantes. A par disso, existe uma vontade imensa da parte de cada professor em dar o melhor de si, para a consecução de altos padrões tanto em seu ensino como nos níveis de aprendizagem dos estudantes, mas também temos de reconhecer que nem todos estão preparados para desenvolver práticas de ensino apropriadas aos níveis 
de exigência que se pedem. Além disso, a maioria dos professores aprendem a leccionar seguindo modelos que não enfatizam a compreensão profunda da matéria, o que significa que teriam de saber mais não somente sobre a matéria que leccionam, mas também sobre como os estudantes aprendem estas disciplinas.

Neste sentido, os professores novatos devem procurar a sabedoria e experiência dos especialistas, escutando suas conversas em salas de professores e seguindo seus conselhos quando a oportunidade se apresenta. Pois, acontece que quando não têm respostas claras para os problemas da sala ou não encontram modelos apropriados à sua tarefa docente, vêem nisso um desafio ao seu sentido de competência profissional e abalado o optimismo já pouco realista com que chegaram ao primeiro encontro com a realidade da instituição de ensino e da aula, e começam a questionar o acerto da sua escolha da actividade docente como carreira (MEDINA e SALVADOR 2009). Eles anseiam o desenvolvimento profissional quando escolhem e adaptam o currículo, quando planificam e desenvolvem sua matéria e gerem o controlo e as actividades da aula; apelam pelo apoio colegial e a ajuda dos professores com experiência. Na melhor das hipóteses eles chegam à instituição achando-se competentes em matérias de ensino e habilidades de trabalho, mas parcos de conhecimento e de experiência, com os alunos, com o currículo, com as rotinas de aula, com as estratégias de ensino, com o desenvolvimento do currículo e com a instituição de ensino, etc.

De um ou de outro modo, os professores principiantes deverão aprender a levar à prática todo o conhecimento teórico anterior que adquiriram durante sua formação inicial, experimentarão todo um manancial de anomalias que encontrarão nesse processo de desenvolvimento e, sobretudo, haverão de aprender a reconstruir o conhecimento anterior mediante sua própria experiência, criando desta maneira conceitos muito mais coerentes sobre aquilo que, para eles, 176 significa o ensino, os estudantes e a escola. É por isso que o desenvolvimento profissional nesta etapa deveria estar muito mais centrado no processo de construção do conhecimento didáctico e não se preocupar apenas pelo domínio de corpos de conhecimentos didácticos já construídos. Quer dizer, a preocupação do professor universitário não deve estar centrada apenas na necessidade do domínio das competências docentes, mas, sobretudo, na necessidade de compreender a «lógica das competências docentes» (Medina et al. 2011: 126) que ele deve lograr e torná-la realidade na docência habitual e ordinária. 
Em suma, os docentes deverão aprender a transformar o conhecimento para que facilitem aos alunos a tarefa de aprender.

\section{O neófito: necessidade de aprender para ensinar}

A partir do acima exposto, coloca-se a seguinte pergunta: o que é que um neófito necessita aprender para aprender a ensinar?

Sem dúvida, os professores principiantes começam por chegar à escola, carregando uma experiência pessoal que decorre desde o tempo passado na escola como estudantes, até obterem as qualificações necessárias para desempenharem as funções de ensino. Ao longo deste período, formaram uma concepção mais ou menos ideal do ensino e dos estudantes e, assim, criaram um sistema de crenças com base em modelos de professores exemplares e uma imagem de si mesmos como aprendizes. Deste modo, os novatos chegam ao ensino com escasso e inadequado conhecimento dos alunos e dos procedimentos a serem seguidos em sala de aula. Em seguida, começam o aprendizado da prática que os faz adquirir conhecimentos, que eles usam para reconstruir sua auto-imagem como professores; logo, ocorre um choque entre as suas próprias crenças e as de seus «conselheiros», uma dissonância que leva à mudança e reformulação de seu sistema de crenças. E, uma vez adquirida uma imagem de si mesmos como professores, é quando o interesse está focado no modelo de instrução, nas necessidades dos alunos e em como os alunos aprendem.

É o período em que os principiantes se preocupam com a aprendizagem de novos procedimentos não adquiridos durante a formação inicial, e, para isso, recorrem tanto à sua experiência de sala de aula quanto às contribuições dos professores mais experientes, que actuam como «orientadores». Esta é uma tarefa cuja realização depende da própria biografia dos professores - auto-imagem, disposição para o desenvolvimento profissional e pessoal e para reconhecer que algumas das suas crenças são incorrectas - da qualidade da formação obtida - a qualidade e quantidade do ensino prático, a informação que lhes foi proporcionada sobre os procedimentos instrutivos utilizados, etc. - e também dos contextos em que desenvolvem suas tarefas docentes - os estudantes, a qualidade dos materiais disponíveis, as relações colegiais e com as famílias, a liderança, o meio em si, etc. 
O acima referido leva-nos a destacar a necessidade de o neófito aumentar sua capacidade de realizar cognições que o façam mais conhecedor daquilo que sabe e do que julga sobre os alunos e o ensino e como essas crenças vão mudando com o decorrer da prática. Isso o conduzirá para um conhecimento cada vez maior e mais profundo dos estudantes, reconstruindo a imagem idealista com a qual entrou no ensino activo e servindo-se disso para reformular, como já referido, sua própria imagem como docente. Isto o leva a criar uma série de rotinas que facilitam a instrução e a gestão da aula, que se torna, desta maneira, mais automatizada. Em última análise, é o que faz com que adquira habilidades, competências e capacidades que lhe permitem resolver com fluidez os problemas da sala de aula, criando repertórios aplicáveis a diferentes contextos em tempos referenciados.

A competência docente requer domínio, mobilização e integração de um conjunto de disposições cognitivas, conhecimentos, habilidades, atitudes e aptidões de diversos tipos, quais sejam: epistemológico, estratégico, linguístico, psicopedagógico, tecnológico e axiológico, que o docente utiliza em contextos complexos, autênticos e únicos. Por outras palavras,

«O conjunto de qualidades que lhe permitem sustentar e empregar um discurso científico a partir do qual gera processos de aprendizagem permanente no sentido pessoal e de grupo com uma visão inovadora para um desenvolvimento proactivo e integral de sua profissionalidade» (SARAVIA 2004: 133).

As competências podem, de certo modo, estar relacionadas com diversas condições como, por exemplo, contextos culturais, institucionais, profissionais, ou outras de carácter social particular; quer dizer, os indivíduos desenvolvem competências de acordo com suas 178 necessidades imediatas, futuras e meio social.

De qualquer maneira, todo o professor deverá analisar o contexto do ensino e seus elementos componentes (pessoais e materiais), seleccionar determinados procedimentos e práticas apropriadas a esse contexto, pô-los em execução e fazer um seguimento contínuo com vista à melhoria. Tudo isso através de um ciclo de planificação, ensino, reflexão e aplicação do conhecimento à prática (LuCAS 1999). Durante a planificação, têm de aprender a tomar decisões fundamentadas no conhecimento dos aprendizes, dos conteúdos e 
do contexto, antecipando possíveis respostas dos estudantes e preparando os materiais e recursos adequados; e isso nos diferentes níveis de solidificação curricular, mas essencialmente na planificação das aulas. Durante o desenvolvimento da aula, deverão introduzir as mudanças oportunas e necessárias naquilo que é planificado em função das condutas dos alunos, para o que se requer capacidade de observação e de reflexão na acção.

Durante sua actividade de ensino, terão de gerir a aula, evitando situações de desordem que impeçam ou dificultem o desenvolvimento normal do ensino, a aprendizagem activa, o trabalho individual e em grupo, a realização de projectos, o trabalho cooperativo, a construção e o uso de materiais, etc. Deverão materializar o ensino, executar o planificado, o que impele o uso de estratégias variadas - conferências, trabalhos de casa, experimentos, etc. -, e aplicar estratégias de avaliação, tanto do aluno como da sua actividade docente (autoavaliação).

Os professores que se estreiam no ensino superior deverão aprender a analisar a sua prática e a do outro, o que significa pensar a relação entre o ensino e a aprendizagem, para que se modifique a comunicação perante os resultados defeituosos de aprendizagem, o que significa serem capazes de reflectir sobre suas acções e avaliar os efeitos que resultam delas, para que possam refinar e melhorar continuamente sua actividade docente. E não somente de forma individual mas colaborativamente, em um tipo de reflexão colegial, como membros de comunidades verdadeiramente críticas e reflexivas. Devem aprender a utilizar em proveito próprio as dissonâncias cognitivas que se produzem em seu contacto com os professores experientes, essencialmente seus «orientadores», e que se sirvam delas para se confrontarem com suas crenças e com as imagens anteriores que possuem sobre o ensino e os alunos, reconhecendo, em função disso, a necessidade de ajustá-las e reformulá-las.

Em parte, se os professores novatos aspiram a encontrar novas formas de ensino, terão de aprender a buscar alternativas, tratando de conectar as ideias através dos diferentes campos e das diversas situações que se manifestam na vida diária das aulas e das instituições de ensino. É um tipo de compreensão que os leva a adquirir a capacidade de transformar o conhecimento da matéria em algo acessível aos estudantes, de transformar o conhecimento per se em conhecimento didáctico do conteúdo (Medina e Salvador 2009), um conhecimento que permite aos professores tornar as ideias 
acessíveis aos outros. É a habilidade de saber em cada momento o que os estudantes conhecem e presumem sobre um determinado tema, e como é possível que, com força intelectual, as novas ideias se fixem nas mentes dos estudantes.

Outra necessidade importante sentida pelos inexperientes refere-se à posse de um tipo de conhecimento baseado na análise e na busca permanente de novas práticas que lhes sirva de alternativa para apoiar as escolhas que realizam no momento de dar respostas aos problemas do ensino. Porque o professor deve, com frequência, pôr em prática seu bom juízo para eleger em cada momento o método ou a estratégia apropriada a cada caso particular, já que não existe um único tipo de prática que possa ser considerada a melhor, mas, sim, depende de cada situação e das condições que a rodeiam; juízo para discernir que estratégias usar para alcançar metas diversas; juízo para elucidar que meios utilizar em cada caso para avaliar os alunos; juízo para decidir que adaptações convêm introduzir no currículo para atender adequadamente os alunos com necessidades educativas especiais.

Além disso, parece que existe uma relação directa entre o domínio de um amplo leque de técnicas por parte do professor, por um lado, e o interesse que se desperta nos estudantes e o tempo que estes investem no trabalho escolar, por outro. Acontece que há professores que continuam acreditando que, variando frequentemente suas estratégias de ensino, esgotam seu acervo e ficam parcos em meios que facilitem a diversificação de acções. Mas a variedade não se encontra no percorrer das unidades que conformam o currículo, e sim nos tratamentos que se aplicam aos diferentes temas. E é que têm uma imagem distorcida do que é uma boa educação; a forma em que eles foram ensinados e o isolamento (Ávila 2003) a que geralmente são submetidos os leva a adquirir um número limitado de estratégias, que são, a todas as luzes, insuficientes.

Os professores principiantes necessitam, sem dúvida, um amplo repertório de estratégias e técnicas de ensino que funcionem com os estudantes aos quais ensinam e no contexto em que trabalham; necessitam estratégias para planificar, desenvolver e avaliar o currículo aplicado a um contexto diverso, um espaço escolar com alunos claramente diferentes. Não se trata de disporem de técnicas aplicáveis a todos os estudantes em todas as situações, mas de que adquiram permanentemente novas capacidades, habilidades e competências usando a investigação sistemática, participando em 
cursos, seminários, palestras, congressos, conferências, experimentar e reflectir sozinho e, particularmente, com outros colegas. Não obstante, o que se verifica é que:

«Os professores universitários não recebem preparação pedagógica específica e mesmo ao longo da sua vida profissional raramente têm a oportunidade de participar em cursos, seminários ou reuniões sobre métodos e avaliação da aprendizagem. A pedagogia fica, portanto, ao sabor dos dotes naturais de cada professor» (GIL 2011: 9).

\section{O professor universitário perante as exigências da sociedade da informação}

Existe hoje uma grande pressão sobre as instituições educativas para formar professores mais competentes e capacitados para responder às exigências do mercado de trabalho. Exige-se proporcionar aos estudantes «os conhecimentos, as habilidades e as atitudes que lhes permitam reconhecer e resolver problemas complexos no seu campo de estudo ou trabalho futuro» (Hoogverld et al. 2005, apud MEdina e Salvador 2009: 454), ou seja, torná-los capazes de resolver os problemas relacionados com sua área de formação e de propor vias de solução daqueles que, porventura, se apresentam como assaz complexos, mobilizando os recursos cognitivos adquiridos durante o período de formação.

No entanto, apesar de não existir ainda uma definição consensual de competência, coincidimos com a conceitualização feita por Perrenoud (2004: 11): "uma competência é a faculdade de mobilizar um conjunto de recursos cognitivos (saberes, capacidades, habilidades, informações, etc.) para solucionar com pertinência e eficácia uma série de situações».

Os termos constituintes dessa definição não diferem dos da definição apresentada por García e Pérez (2008: 6), no que diz respeito ao alcance e à extensão do significado dos mesmos. Em García e Pérez aparecem diversos termos, como, por exemplo, conhecimentos, habilidades, atitudes, atribuições, aptidões, hábitos, valores, emoções, etc. Os professores principiantes acreditam que a competência de ensino requer demonstração, uma base de conhecimentos, gestão efectiva da aula, comunicação pessoal com os envolvidos e consciência de seu papel como professor. A competência está 
intrinsecamente relacionada com as habilidades individuais e a execução satisfatória e apropriada de tarefas.

De qualquer modo, a difícil tarefa de tornar-se professor, com toda carga afectiva implícita, com o enorme cúmulo de competências que se devem dominar, com a ampla série de questões que a socialização coloca, necessita indubitavelmente de uma atenção esmerada, um cuidado exemplar de todo o processo, para o qual é imprescindível dispor dos meios adequados e suficientes; meios que ajudem a reformulação das crenças prévias, desenhando para os docentes inexperientes contextos apropriados que respondam não somente aos imperativos morais e culturais que a educação de adolescentes e jovens comporta, mas também ao enorme desafio de convencê-los da importância de formação contínua e da construção das melhores condições para a aprendizagem. Meios que os ajudem, primeiro, a identificarem, e, depois, a dominar a incerteza da prática; que facilitem a aquisição de hábitos que lhes permitam desafiar os modos típicos de aprendizagem; que lhes permitam confrontar o status quo e as assunções que se dão sobre sua própria identidade profissional, seu «eu como professor» (MEDINA: 2001) e suas teorias sobre o ensino e a aprendizagem.

Vivemos numa era em que prima o conhecimento. $\mathrm{O}$ valor do mercado estima mais o desenho do que o próprio produto; o verdadeiro valor não está, como acontecia em outros tempos, nos instrumentos de trabalho, pelo contrário estes são secundários em relação ao processo criativo dos trabalhadores, que são, na realidade, os meios de produção. É nesta perspectiva que Layer (2004) apela à adequação do ensino superior ao mundo laboral, e Semeijin et al. (2005) responsabilizam a universidade na preparação de estudantes para a integração no mercado de trabalho.

A economia atual depende essencialmente do intelecto e da aplicação de ideias. Os instrumentos do trabalhador moderno estão re182 feridos ou relacionados à informação e podem ser encontrados em qualquer lugar, inclusive nas residências dos próprios trabalhadores (computadores e redes telemáticas). O valor real que estes instrumentos fornecem ao mundo do trabalho (empresas, serviços...) radica no conhecimento que os indivíduos possuem e em sua criatividade, em sua capacidade de manifestar e utilizar o pensamento crítico, reflexivo e divergente.

Mas não é o conhecimento per se, e sim sua dinâmica, sua natureza mutável que o faz verdadeiramente valioso. Por isso, «hoje, o 
que mais interessa é a aquisição de uma mentalidade científica, o desenvolvimento das capacidades de análise, síntese e avaliação, bem como o aprimoramento da imaginação criadora» (GIL 2011: 8). Como afirma Thornburg (2002, apud Medina e SAlvador 2009: 456), referindo-se aos grémios da Idade Média e aos trabalhadores da era industrial, «o poder mudou em mãos dos trabalhadores. $O$ trabalho já não é permutável e as pessoas já não podem ser tratadas como elos numa máquina industrial».

E se o mundo laboral está mudando aceleradamente, não é estranho que a sociedade apele por uma formação superior diferente, porquanto se exige ao trabalhador outras habilidades, competências e aptidões e um conhecimento mais amplo e diferenciado. Uma formação baseada no conhecimento, no domínio e na transformação contínua das competências docentes, consideradas necessárias para avançar no desenvolvimento das competências discentes. Contudo, a necessidade de harmonizar e dominar competências deve ser articulada com a necessidade de ser um docente, formador e um prático como profissional competente (Le Boterf 2010, apud MEDINA et al. 2011).

O sentido dos conceitos de espaço e tempo deve ser entendido agora de maneira radicalmente diferente, tanto quanto espaços e tempos educacionais (De Vicente 1998a). O ensino faz-se aqui e agora; lugar e tempo aparecem como duas dimensões acomodadas às exigências desta nova classe de trabalhadores, de quem se espera habilidade para descobrir significados e compreender modelos, habilidades para resolver problemas no quadro de um sistema complexo com os elementos inter-relacionados, habilidade para trabalhar em equipa, capaz de lidar simultaneamente com múltiplas disciplinas e de descobrir novas vias de resolução de problemas.

Diante da concepção dos modelos tradicionais de ensino centralizados em um edifício escolar, aberto apenas algumas horas ao dia, durante alguns meses do ano, aparece o ensino através de meios informáticos, em linha, que proporcionam informação em qualquer lugar e a todo o tempo. A tecnologia apresenta-se como uma alternativa válida para responder às necessidades desta era e às do futuro. Os computadores pessoais permitem aos estudantes começar e parar suas actividades em qualquer momento e no lugar em que eles se encontrem. O mecanismo é tão fácil como sublinhar com um marcador na página do livro cuja leitura interrompemos. 
Tudo isso representa um desafio para a nova escola, um desafio que há-de ser mais humano do que tecnológico, mas que obrigará a uma adopção de novos currículos e métodos inovadores de ensino, vai obrigar a examinar assunções que durante décadas permaneceram inalteráveis, vai obrigar a mudar as crenças e atitudes dos pais, dos gestores, dos próprios estudantes, dos claustros de professores e, sobretudo, dos docentes e dos formadores de professores.

Mas, "a instituição educativa também deve mudar, deve converter-se em algo verdadeiramente educativo e superar seu conceito já obsoleto que remonta ao século XIX» (IMBERNón 2005: 96). Implica necessariamente que se fale da instituição educativa não tanto como «um lugar», e sim como uma manifestação de vida em toda sua complexidade, em toda sua rede de relações e dispositivos com uma comunidade educativa, que tem um modo institucional de conhecer e de querer ser (ibidem).

Para que isto se efective, haverá necessidade de partir da atitude tradicional de ensinar para encaminhar alguma matéria a alguns estudantes em um lugar determinado e em um tempo definido à criação de âmbitos que permitam a todos os alunos aprender qualquer coisa em qualquer lugar e a qualquer tempo (momento), com recurso à tecnologia disponível.

Em primeiro lugar, porque se necessita de instrumentos que ajudem os professores a uma revisão contínua da prática, de maneira a dispor a todo o momento do feedback sobre sua própria atuação e sobre os efeitos que derivam dela. Porque a avaliação é o verdadeiro motor da mudança, é um agente primordial, senão crítico, em qualquer reforma do ensino; é como a roda que põe em movimento toda a maquinaria do aperfeiçoamento do professor, da turma e da escola. No entanto, para os professores mudarem, há que lhes proporcionar ocasiões - espaço e tempo - que lhes permitam modelar práticas apropriadas e os melhores procedimentos e instrumentos que lhes facilitem desenvolver com eficácia o exercício de sua profissão (L'ANson et al. 2003), que os ajudem a construir e reconstruir em um processo contínuo seu conhecimento profissional, o conhecimento profissional que lhes é idiossincrásico, mas que se encontra constantemente submetido a modificações. Alguns recursos efectivos ajudam, sem dúvida, a melhorar a prática, o que levará a melhorar o desempenho do aluno, que na verdade é o objectivo principal de todo o quadro da educação. 
Em segundo lugar, a reflexão fornecerá ao professor principiante uma arma com um poder extraordinário, porquanto é dela e a partir dela que se produzem os processos cognitivos (LEE 2005) que permitem analisar a prática própria e a dos outros, que irá capacitá-lo para expressar suas teorias pessoais sobre o ensino e os estudantes, seu conhecimento tácito e seu sistema de crenças em que problematiza e dá sentido à sua prática. Permite-lhe conhecer os motores propulsores de suas acções e das decisões que toma, ajudando-o a estabelecer sua identidade. Mas, apesar de a reflexão ser um processo cognitivo pelo qual se revela a nossa própria experiência, enquanto chamada para as nossas experiências passadas, um retrocesso no tempo, é também revelado como uma conexão com o futuro. Como assevera De Vicente (200ob: 934):

«A reflexão revela um mundo de relações entre os diferentes aspectos de nossa própria experiência vivida, mas também experiências passadas, para se conectar com a nova informação recebida da presente situação; e nos permite tirar conclusões a partir do passado e desenvolver novas ideias e conceitos para aplicá-los às nossas actividades futuras».

Em terceiro lugar, a colegialidade - a formação de professores com base na escola, escolas de desenvolvimento profissional e outros modelos de prática colaborativa - irá permitir a reflexão colaborativa, irá possibilitar aos professores falarem uns com os outros sobre suas práticas, que conferem direito a observar o outro e, em seguida, analisar e discutir as suas performances em sessões de «treinamento» ou diálogos profissionais, irá habilitá-los a planejar em conjunto, desenhar, avaliar, inovar e investigar e preparar materiais didácticos e práticas de ensino para partilhar.

Não se trata de acções isoladas, mas da criação de uma verdadeira cultura de colaboração, capaz de acolher inovações poderosas, novos papéis para os professores, mais autonomia e responsabilidade e maior descentralização no processo de tomada de decisões. Tudo isso deve decorrer nos limites assinalados por Shulman (1989): «O colégio visível», com relações cara-a-cara através da orientação, do treinamento, da modelação, da análise de casos, etc., e o «colégio invisível», que perpassa os muros da escola difundindo experiências e casos para a reflexão, comentários escritos de professores e redes conformadas pelos modernos meios de comunicação e as 
novas tecnologias, que potenciam o crescimento profissional dos orientadores, dos formadores de professores, dos especialistas em educação e, em particular, dos professores, essencialmente os principiantes.

O uso de modelos baseados na conversa também ajuda o professor principiante a aprender a ensinar, o que requer o apoio incondicional do contexto social, que permite que os especialistas em educação ou em áreas específicas da mesma «façam ouvir as suas vozes». Porque, como Freire (1979) afirma, a educação inclui acções que vão além da dimensão física simples de instrução. A conversa deve ser mais do que um diálogo sobre um tema específico, deve ser um verdadeiro intercâmbio de ideias que ajudam a entender as histórias comuns sobre como se aprende a ensinar. Deve ser uma força capaz de arrancar do nosso subconsciente os conhecimentos que temos tacitamente, elevando-os, articulando-os e conectandoos com o anteriormente adquirido.

Os procedimentos acima referidos devem ser pensados, sem dúvida, não isolada e independentemente, mas a partir da relação íntima que mantêm entre si, e também a partir de sua conexão com outros elementos que são, às vezes, difíceis de explicar por se sobreporem ao nosso conhecimento actual. Referimo-nos ao conhecimento e às crenças dos professores, às rotinas e à intuição, como três formas de comportamento demonstrado pelos professores: acções de rotina, acções reflectidas e percepções adquiridas sem a instantânea concorrência do raciocínio; todos eles ligados no imprescindível marco da colaboração (DE VICENTE 200ob).

Tomando em consideração os três tipos de conhecimento - conhecimento «para a prática» (formal), «na prática» (pessoal) e «da prática» (pesquisador) - e os três tipos de reflexão - «sobre a prática», «na prática» e "para a prática» (MEdINA e SAlvaDOR 2009), podemos inferir que a formação didáctico-pedagógica do professor universitário é essencial para a melhoria da docência universitária, pois se constitui no protagonista das transformações da cultura e das práticas docentes nas universidades. Além disso, o professor universitário está consolidado como artífice da liderança formativa para todos os docentes do sistema de educação, dado que a universidade - assim o demonstra a maioria, se não todos os estudos - converteu-se em legitimadora da inovação da educação, previdente dos desafios da sociedade do conhecimento e criadora da nova cultura que esta sociedade exige. 
Deste modo, a formação em docência transforma-se na actividade essencial dos professores diante dos desafios das TIC, da interculturalidade, da transversalidade dos saberes e das inovações sócio-laborais para os estudantes. Esta transformação permanente do sentido do saber e das responsabilidades tecnológicas deve ser encarada pelos professores como uma exigência profissional, dado que cada docente tem de aspirar a inquirir e reflectir sobre sua prática, a aprender dela e a partilhar com os colegas o grande desafio da docência: a contínua melhoria do processo de ensino e aprendizagem.

\section{Conclusão}

A discussão apresentada em torno da formação didáctico-pedagógica do professor universitário principiante procurou mostrar que ela é hoje um imperativo social inadiável, resultado da pressão que a sociedade da era do conhecimento exerce sobre os diversos sectores que a constituem, com maior incidência sobre o da educação. A sociedade está exigindo da universidade a formação de jovens profissionais altamente competentes, porque o desenvolvimento está conectado com os resultados do sistema educativo. Está a pedir à universidade que proporcione aos estudantes os conhecimentos, as habilidades e as atitudes que lhes permitam identificar e resolver problemas complexos na sua área de conhecimento ou estudo e em trabalhos futuros, porque a economia actual depende essencialmente do intelecto e da aplicação de ideias.

Diante destas novas exigências da sociedade, um grande desafio para os gestores, os professores e os decisores políticos, em pleno século xxI, é o de tudo fazerem para criarem um contexto escolar apropriado para a formação didáctico-pedagógica dos professores principiantes, a fim de dotá-los de competências que favoreçam o bom desenvolvimento da actividade mais representativa da aç̧ão docente, o ensino. A formação didáctica do professor principiante permite que este amplie o saber pedagógico, posto que a didáctica facilita ao professor o conhecimento dos métodos e modelos mais apropriados para tomar as decisões mais ajustadas aos processos de ensino-aprendizagem, a escolha do projecto de ensino em coerência com as necessidades e as expectativas de todos os estudantes e participantes do processo de ensino. 
Essa formação deve ser acompanhada de uma concepção de didáctica apoiada na reflexão colaborativa, que busca, a partir da prática, o aperfeiçoamento de habilidades, aptidões e competências docentes que permitam orientar e comunicar com clareza o conhecimento de que os estudantes necessitam para desenvolverem o pensamento crítico e criativo. Hoje, é exigido ao professor universitário não somente um discurso bem articulado, nalguns casos embelezado pelo carisma de quem o pronuncia, como também um fecundo conhecimento da didáctica e sua adaptação às contínuas situações de mudança do processo ensino-aprendizagem.

A formação didáctica é um imperativo que se desloca da esfera normativa para o campo do saber prático, na medida em que melhora os processos comunicativos, orienta e situa o professor na linha das finalidades educativas e do desenvolvimento apropriado do processo de ensino-aprendizagem. O princípio de que «os professores necessitam somente o conhecimento da matéria» não apenas se tornou obsoleto, face às exigências actuais sobre a educação, mas é também inviável, porque recusa qualquer programa de formação e aceita qualquer rota alternativa à profissão docente.

A formação didáctica do professor universitário principiante deveria ser articulada com algumas técnicas didáctico-pedagógicas, como a conversa. Esta permite ao principiante aprender, para aprender a ensinar, escutando, por meio do diálogo, os professores experientes. A conversa deve ser dirigida directamente à reflexão sobre aspectos tais como o ensino, o professor ou os estudantes, colocando e respondendo, interactivamente, questões pertinentes ao processo de ensino e aprendizagem, como: para quê formar os estudantes e que desenvolvimento profissional os professores necessitam, quem são os nossos estudantes e como aprendem, o que implica a actualização do saber, e especialmente como realizar a actividade de ensino ao desenvolver o sistema metodológico do docente.

Conversar sobre aspectos relacionados com o ensino representa a colaboração entre duas ou mais pessoas - professores, orientadores, supervisores... - para promover a reflexão, entendida não como um comportamento aprendido ou habilidade, mas sim como uma atitude, como algo que nos torna inquiridores, situa-nos no meio da prática para falar sobre possibilidades, sobre questões problemáticas e não em certezas. Trata-se de raciocinar sobre o processo para, a partir da desconfiança e do cepticismo do pesquisador 
curioso, entender nossas acções de forma mais profunda. Através de conversas (argumentos, diálogos profissionais), podem revelar--se, por exemplo, diferentes maneiras de entender a matéria. Essas conversas são importantes na medida em que ajudam a socialização dos professores principiantes. Apesar da certeza de entrarem na profissão de ensino com um grau de conhecimento da matéria a ser ensinada, com um certo grau de habilidade e domínio do assunto, não é provável que tenham a competência necessária para transformar essa matéria em algo de fácil acesso.

\section{Referências bibliográficas}

Ávila J.

2003, «Trained for isolation: the impact of departmental cultures on student teachers' views and practices of collaboration», Journal of Education for Teaching, vol. 29, n. ${ }^{\circ}$ 3, pp. 197-217.

Awaya A.; Mcewan H.; Heyler D.; Linsky S.; Lum D.; Wakukawa P. 2003, "Mentoring as a journey», Teaching and Teacher Education, vol. 19, n. ${ }^{\circ}$ 1, pp. 45-56.

De la Hoz G., ver Hoz G. de la, infra

De Vicente, P. S., ver Vicente P. S. de, infra

FERACINE L.

1990, O professor como agente de mudança social. São Paulo, EPU.

FREIRE P.

1979 (21. ${ }^{a}$ edição), Pedagogía del oprimido. Madrid, Siglo XXI.

GAL N.

2006, «The role of practicum supervisors in behaviour management education», Teaching and Teacher Education, vol. 22, n. ${ }^{\circ}$, pp. 377-393.

García J. V. e PÉrez M. C.

2008, «Espacio europeo de educación superior: competencias profesionales y empleabilidad», Revista Iberoamericana de Educación, n. ${ }^{\circ}$ 46, pp. 1-12.

GIL A. C.

2011 (1. ${ }^{\mathrm{a}}$ edição, 6. ${ }^{\mathrm{a}}$ reimptressão), Didática do ensino superior. São Paulo, Atlas.

Hamzah M. S. G.; Mohamad H.; Ghorbani M. R. 2008, «Excellent teachers' thinking model: implications for effective 
teaching», Australian Journal of Teacher Education, vol. 33, n. ${ }^{\circ}$ 4, pp. 11-27.

Hoz G. de la

2009, Los médicos y la educación médica: una mirada desde la teoría sobre la formación de competencias socio-profesionales en el profesorado universitario. Barranquilla, Universidad Libre.

IMBERNÓN F.

2005 ( $5 \cdot^{\mathrm{a}}$ edição), Formação docente e profissional: formar-se para a mudança e a incerteza. São Paulo, Cortez.

L'ANSON J.; Rodrigues S.; Wilson G.

2003, "Mirrors, reflections and refractions: the contribution of microteaching to reflective practice», European Journal of Teaching Education, vol. 26, n. ${ }^{\circ}$ 2, pp. 189-199.

LAYER G.

2004, Widening participation and employability. New York, Learning and Teaching Support Network.

LEE H. J.

2005, "Understanding and assessing preservice teachers' reflective thinking», Teaching and Teacher Education, vol. 21, n. ${ }^{\circ}$ 6, pp. 699-715.

LiBÂNEO J. C.

1994. Didática. São Paulo, Cortez.

LuCAS C. A.

1999, «Developing competent practitioners», Educational Leadership, vol. $56,{ }^{\circ}{ }^{\circ} 8$, pp. $45^{-48}$.

Masetto M. T.

1997 ( $4{ }^{\text {a }}$ edição), Didática: A aula como centro. São Paulo, FTD.

Medina A.; Domínguez M. C.; Gonçalves F. R.

2011, «Formación del profesorado universitario en las competencias docentes", Revista Historia de la Educación Latinoamericana, vol. 13, n. $^{\circ} 17$, pp. 119-138.

Medina A.

2001, «Formación del profesorado: Modelos y prácticas formativas en el centro y aula», in Didáctica general para psicopedagogos. Madrid, Universidad Nacional de Educación a Distancia.

Medina A. e Salvador F. (coords.) 2009, Didáctica general. Madrid, Pearson Educación.

Perrenoud P.

2004, Diez nuevas competencias para enseñar. Barcelona, Graó. 
SARAVIA G. M. A.

2004, Evaluación del profesorado universitario: un enfoque desde la competencia profesional. Tesis doctoral. Universidad de Barcelona.

SEMEIJIN J. et al.

2005, Competence indicators in academic education and early labour market success of graduates in health sciences. Maastricht, Research Centre for Education and the Labour Market.

SHULMAN L.

1989, «Those who understand: Knowledge growth in teaching», Educational Researcher, vol. 15, n. ${ }^{\circ}$ 2, pp. 4-14.

SOARES A.; Lock R.; Foster J.

2008, «Induction: The experiences of newly qualified science teachers», Journal of Education for Teaching, vol. 34, n. ${ }^{\circ}$ 3, pp. 191-206.

VEENMAN S.

1984, «Perceived problems of beginning teachers», Review of Educational Research, vol. 52, n. ${ }^{\circ}$ 2, pp. 143-178.

ViCENTE P. S. de

2000a, «Variaciones sobre un vínculo inquebrantable: El papel de las nuevas tecnologías en el desarrollo profesional del docente», in Y continuamos avanzando: Las nuevas tecnologías para la mejora educativa. Sevilla, Kronos.

200ob, «Un buen velero para aprender navegación: Organizando los elementos del contexto para el desarrollo profesional del docente», in Las organizaciones educativas en la sociedad neoliberal, volume II. Granada, Grupo Editorial Universitario.

1998, «Espacio y tiempo: Dos constructos clave para el desarrollo profesional de los docentes» in Enfoques en la organización y dirección de instituciones educativas formales y no formales. Granada, Grupo Editorial Universitario.

VILLAR L. M. e Alegre O.

2009, "Investigación evaluativa de un título propio: Máster educar en la diversidad», Enseñanza \& Teaching, vol. 27, n. ${ }^{0}$ 2, pp. 17-44.

ZaBALZA M. A.

2006, Competencias docentes del profesorado universitario: calidad y desarrollo profesional. Madrid, Narcea. 
Title: The need for didactic-pedagogical training of the beginning university professor

\begin{abstract}
This text aims to address the issue related to the formation of the fledgling university teacher, taking into account that the task of education in Angola is promoted by challenges that encourage teachers to reflect on a higher education rigorous and objective able to provide the citizen training with quality. But empirical evidence of teaching practice indicates that for this wish come true is to abandon the current perspective, for example, novice teachers start teaching as teachers of the subject without proper monitoring of an experienced teacher, as well as making it mandatory the certificate of pedagogic aggregation.
\end{abstract}

Keywords: Training; teaching; Pedagogy; Activity; Professor novice.

\title{
António Inácio Rocha Santana
}

Sociólogo, exerce desde 2010, em comissão de serviço, a função de Director-Geral da Escola Superior Pedagógica do Kwanza Norte. É docente do Departamento de Sociologia (DS) da Faculdade de Ciências Sociais (FCS) da Universidade Agostinho Neto (UAN). Doutorado em Sociologia (2005) pelo Instituto de Sociología y Estudios Campesinos de la Universidad de Córdoba, Reino da Espanha e Doutorado em Ciências da Educação (2015) pela School of Social and Human Studies of the Atlantic International University, Estados Unidos da América (EUA). Tem participado com comunicação em alguns eventos nacionais e estrangeiros e dentre os quais se regista: «La comunicación docente: los comentarios de los estudiantes acerca de la actitud de los docentes en el aula», comunicação apresentada ao Congresso Pedagogía 2015, Palácio de Convenciones de La Habana, de 26 a 30 de Janeiro de 2015; «As manifestações do preconceito de cor em Angola», comunicação apresentada na 2. ${ }^{a}$ Conferência Internacional do CONCLADIN - Centro de Estudos das Culturas e Línguas Africanas e da Diáspora Negra, São Paulo, Universidade Estadual de São Paulo, Araraquara, Brasil, 18 a 21 de Maio de 2009; "África: imaginário, independência e desenvolvimento» Conversa temática apresentada aos estudantes de pós--graduação na 2. ${ }^{a}$ Conferência Internacional do Centro de estudos das Culturas e Línguas Africanas e da Diáspora Negra (CONCLADIN), São Paulo, Universidade Estadual de São Paulo, Araraquara - Brasil, 18 a 21 de Maio de 2009; "A imigração colonial portuguesa a Angola: um processo de construção de um projecto nacional para o porvir», comunicação apresentada no $x$ Congresso Luso-Afro-Brasileiro de Ciências Sociais, Braga, Universidade do Minho, de 4-7 de Fevereiro de 2009. Publicou, "As três formas históricas de desenvolvimento rural: uma breve incursão no contexto teórico do seu surgimento", Revista Letras e Ciências Sociais, n. ${ }^{0}$ 1, Janeiro-Junho de 2010, pp. 55-71.

[e-mail: antoniosantana20oo@yahoo.es] 